\title{
In vitro Antioxidant and Free Radical Scavenging Activity of the Bark of Dillenia indica L.
}

\author{
Mst. Jasmin Akter', Rafeza Khatun ${ }^{2}$, Naznin Ara Khatune ${ }^{1}$, AHM Khurshid Alam ${ }^{1}$ \\ and Md. Aziz Abdur Rahman ${ }^{1}$ \\ ${ }^{1}$ Department of Pharmacy, University of Rajshahi, Rajshahi, Bangladesh \\ ${ }^{2}$ Department of Pharmacy, Comilla University, Comilla, Bangladesh
}

(Received: December 7, 2021; Accepted: January 18, 2022; Published (web): January 29, 2022.)

\begin{abstract}
The aim of the study was to explore the antioxidant and free radical scavenging activity of bark of Dillenia indica L. The methanolic extract (CME) of coarse powder of the dried bark was fractionated with pet-ether (PETF), chloroform (CHF), and water (AQF) and each fraction was investigated for antioxidant and free radical potentials. The phenolic contents of CME, CHF, PETF and AQF were found to be $90.2,171.1,52.1$ and 158.1 and flavonoid contents $182.6,340.2,285.9$, and $362.6 \mathrm{mg}$ of GAE/g of dried extract, respectively. The total antioxidant activity of CME, PETF, CHF, AQF and standard catechin in terms of absorbance were $0.373,0.707,0.88,1.051$ and 0.804 , respectively at $160 \mu \mathrm{g} / \mathrm{ml}$ concentration indicating $\mathrm{AQF}$ possessing the highest total antioxidant activity. In DPPH radical scavenging activity, the $\mathrm{AQF}$ and $\mathrm{CHF}$ showed potential radical scavenging activity followed by CME and PETF with $\mathrm{IC}_{50}$ values of 1.5, 2.5, 23 and $61 \mu \mathrm{g} / \mathrm{ml}$, respectively, whereas standard ascorbic acid showed $\mathrm{IC}_{50}$ at $8 \mu \mathrm{g} / \mathrm{ml}$. Among the extractives, $\mathrm{AQF}$ and $\mathrm{CHF}$ exhibited potent hydroxyl radical scavenging activity with $\mathrm{IC}_{50}$ values of 49.0 and $42 \mu \mathrm{g} / \mathrm{ml}$ followed by CME and PETF with $\mathrm{IC}_{50}$ of 86 and $168 \mu \mathrm{g} / \mathrm{ml}$, respectively. In ferric-reducing antioxidant assay, AQF, CHF and CME (absorbance $2.262,2.418$ and 2.157, respectively) showed higher activity than that of standard (1.793) followed by PETF (absorbance 0.593). Since polyphenols like flavonoids play a vital role in controlling antioxidants, polyphenol rich extracts are potent source of antioxidants. Our data showed that the chloroform fraction of the bark of $D$. indica provided highest polyphenols and antioxidant activities, hence, can be used further as a source of natural antioxidants.
\end{abstract}

Key words: Dillenia indica, Dilleniaceae, Polyphenols, Free radicals, Antioxidant activity.

\section{Introduction}

Generation of free radicals (reactive oxygen species, ROS) inside biological system gives rise to oxidative stress (OS) that plays a role in a variety of diseases, including cancer, neurodegenerative disorder, heart disease, rheumatoid arthritis and in the aging process (Das et at., 2021; Alam et al., 2016). Exogenous as well as endogenous antioxidants are free radical scavenging agents that play a role against the development of chronic, age-related degenerative diseases, hence, dietary antioxidants lower the risk of these disease (Sharifi-Rad et al., 2020). In addition to health benefit, antioxidants prevent or delay oxidation of food that are initiated by free radical formation during their exposure to environmental factors such as light, air and temperature (Franco et al., 2019). At present a significant number of antioxidants are synthesized as medicines that produce various side effects in vivo (Xu et al., 2021).

From ancient time, plants have been used in traditional medicine in most of the civilized cultures and tribes and are proven to be the potential source of 
natural antioxidants (Reza et al., 2021). Flavonoids, polyphenols, carotenoids, folic acid, trans-cinnamic acids, tocopherols, etc., are some of the important antioxidants produced by the plant kingdom for their sustenance. The plant Dillenia indica L. (family Dilleniaceae), available in various parts of Bangladesh and are locally called Chalta, has a wide variety of folkloric reputation (Akter et al., 2021). It is used by the rural people in the treatment of fever, constipation, dysentery, stomach ache, snake bite, burning sensation in the chest, food poisoning, bacterial infection, diabetes, etc. (Saiful and Armania, 2014). A growing body of evidence has revealed the potential of whole plant of $D$. indica as a source of various antioxidants, including polyphenols (Rahayu et al., 2020), flavonoids (Saha et al., 2009), triterpenoids and steroids (Kumar et al., 2011), etc. There is no complete data on total phenolic and flavonoid content, antioxidant capacity, radical scavenging activity and ferric reducing activity of extracts from $D$. indica bark. Hence, the aim of the current study was to determine the total phenolic and flavonoid content and total antioxidant activity of the extracts and their free radical scavenging activity.

\section{Materials and Methods}

Collection and preparation of plant materials: $D$. indica bark was purchased from Dinajpur, Bangladesh, in October-November, 2020 and was identified by taxonomist. A voucher specimen (JU/32234) is deposited at the Bangladesh National Herbarium. The collected stem bark was washed with tap water, shade dried for several days with occasional sun drying followed by oven drying at 45 ${ }^{\circ} \mathrm{C}$ for 24 hours and was ground into coarse powder. The powdered bark was kept in air tight container at room temperature.

Preparation of extract: Powdered bark (500 g) was soaked in about $1500 \mathrm{ml}$ methanol in an ambercolored container. The sealed container was occasionally shacked and stirred for 6-7 days and after 7 days extract was filtered through cotton filter followed by filter paper, concentrated by rotary evaporator in reduced pressure and preserved at $4{ }^{\circ} \mathrm{C}$
(40 g, CME). After dilution with water, the CME was partitioned with pet-ether followed by chloroform to get petroleum ether (PETF), chloroform (CHF), and finally aqueous (AQF) fractions (Rahman et al., 2015).

Determination of total phenolics: The total phenolic content (TPC) of the samples was determined using method described by Wolfe et al., 2003. An aliquot was mixed with $2 \mathrm{ml}(75 \mathrm{~g} / \mathrm{l})$ of $\mathrm{Na}_{2} \mathrm{CO}_{3}$ in a tube and diluted $2 \mathrm{ml}$ Folin-Ciocalteu reagent. The tube was vortexed $(15 \mathrm{sec}$.) and allowed to stand for 20 minutes at $25^{\circ} \mathrm{C}$ for color development. Absorbance (at $760 \mathrm{~nm}$ ) was measured using Shimadzu spectrophotometer and the result was expressed in terms of standard gallic acid equivalent (mg of GA per gram of bark extract). Each experiment was performed in triplicate.

Determination of total flavonoids: Total flavonoids (TFC) were estimated using $\mathrm{AlCl}_{3}$ colorimetric assay described by Ordonez et al., 2006. $100 \mu \mathrm{l}$ of $10 \% \mathrm{AlCl}_{3}, 1.5 \mathrm{ml}$ of $\mathrm{MeOH}, 100 \mu \mathrm{l}$ of $1 \mathrm{M}$ potassium acetate solution and $2.8 \mathrm{ml}$ of distilled water were added to $0.5 \mathrm{ml}$ of sample. The absorbance (at $420 \mathrm{~nm}$ ) was measured in UV spectrophotometry after 90 minutes of incubation at $25{ }^{\circ} \mathrm{C}$. The result was expressed in terms of catechin equivalent ( $\mathrm{mg}$ of catechin per gram of dry bark extract).

Determination of total antioxidant capacity: Total antioxidant capacity (TAC) was calculated by method described by Prieto et al., (1999). In brief, samples at different concentrations (each $0.5 \mathrm{ml}$ ) was mixed with $3 \mathrm{ml}$ of $\mathrm{H}_{2} \mathrm{SO}_{4}(0.6 \mathrm{M}), \mathrm{Na}_{3} \mathrm{PO}_{4}(28 \mathrm{mM})$ and ammonium molybdate (1\%) mixture. The absorbance (at $695 \mathrm{~nm}$ ) of samples was measured after incubation at $95^{\circ} \mathrm{C}$ for $10 \mathrm{~min}$. Increased absorbance is the indication of increased total antioxidant capacity.

DPPH free radical scavenging assay: DPPH, common abbreviation for 2,2-diphenyl-1-picrylhydrazyl is a chemical used to determine free radical scavenging potential (DRSA). The assay was performed using modified method described by Kedare and Singh, 2011. $2.4 \mathrm{ml}$ of DPPH $(0.1 \mathrm{mM})$ 
in $\mathrm{MeOH}$ solution was mixed with $1.6 \mathrm{ml}$ of methanolic samples of various concentrations. The mixture was vortexed, left in the dark (25-30 minutes) and the absorbance (at $517 \mathrm{~nm}$ ) were measured to calculate $\%$ of DRSA by "inhibition $\%=$ [ $\left.\left(\mathrm{A}_{0}-\mathrm{A}_{1}\right) \mathrm{A}_{0}\right] \times 100$ " equation, where $\mathrm{A}_{0}$ is the absorbance of control and $A_{1}$ is that of extractives. From $\%$ of inhibition vs concentration curve " $\mathrm{IC}_{50}$ " was calculated.

Hydroxyl radical-scavenging assay: Hydroxyl radical-scavenging assay (HRSA) was performed by modified method of Klein et al. (1981). $500 \mu$ of extract $(1 \mathrm{mg} / \mathrm{ml}$ in $70 \% \mathrm{MeOH})$ was taken in test tube and following reagents were added to it: $100 \mu \mathrm{l}$ of $\mathrm{H}_{2} \mathrm{O}_{2}(1.0 \mathrm{mM}), 100 \mu \mathrm{l}$ of 2-deoxy D-ribose (28 $\mathrm{mM}), 100 \mu \mathrm{L}$ of EDTA $(1.04 \mathrm{mM}), 100 \mu \mathrm{l}$ of $\mathrm{FeCl}_{3}$ $(200 \mu \mathrm{m})$ and $100 \mu \mathrm{l}$ of ascorbic acid $(1 \mathrm{mM})$. The mixtures were incubated for $1 \mathrm{hr}$ at $37{ }^{\circ} \mathrm{C}$ and $10 \%$ TCA and $1 \%$ TBA $(1 \mathrm{ml}$ each) were added in each test tube. Finally, mixtures are incubated at $100{ }^{\circ} \mathrm{C}$ (for 20 minutes) and the absorbance (at $532 \mathrm{~nm}$ ) were taken to calculate $\%$ HRSA by " $\%=\left[\left(\mathrm{A}_{0}-\mathrm{A}_{1}\right) / \mathrm{A}_{0}\right]$ $\times 100$ ", where $A_{0}$ is the absorbance of control and $A_{1}$, extractive. From curve $\mathrm{IC}_{50}$ was calculated.

Determination of ferric-reducing antioxidant capacity: Oyaizu (1986) described the ferric reducing capacity (FRC) method. In the method, $0.25 \mathrm{ml}$ of different diluted samples were added to $0.625 \mathrm{~mL}$ of $0.2 \mathrm{M}$ potassium buffer and $0.625 \mathrm{~mL}$ of $1 \%$ $\left[\mathrm{K}_{3} \mathrm{Fe}(\mathrm{CN})_{6}\right]$ solution and the mixture was incubated for $20 \mathrm{~min}$ at $50{ }^{\circ} \mathrm{C}$. After that, $0.625 \mathrm{ml} \mathrm{TCA}(10 \%$ solution) was added followed by centrifuged at 3000

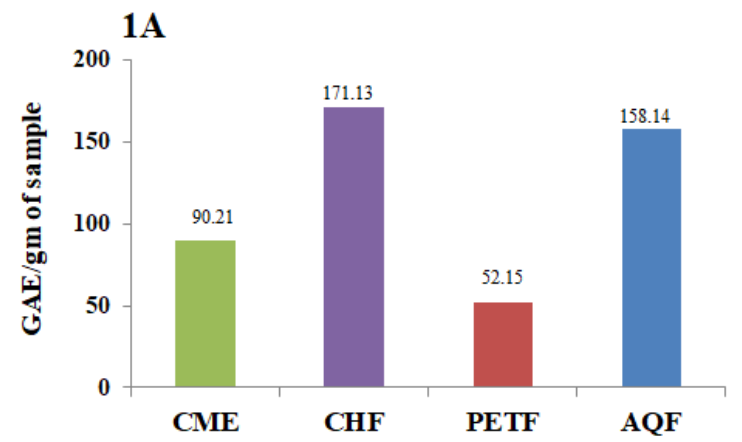

rpm (for $10 \mathrm{~min}$ ). Lastly, $1.8 \mathrm{ml}$ supernatant was withdrawn and mixed with distilled water $(1.8 \mathrm{ml})$ and $0.1 \% \mathrm{FeCl}_{3}(0.36 \mathrm{ml})$ solution. The absorbance (700 nm) of solution was measured and found an increased absorbance is the indication of increased ferric reducing capacity.

\section{Results and Discussion}

Amount of bark extract and its fractions: The dried coarse powder of $D$. indica $(500 \mathrm{~g})$ was extracted with $1500 \mathrm{ml}$ methanol for 7 days (3 times) and the mixtures were combined, filtered and concentrated to get $40 \mathrm{~g}$ concentrated brownish mass. After dilution with adequate amount of water, the extract was partitioned with pet-ether, chloroform and water to get PETF ( $9.8 \mathrm{~g}, 24.5 \%$ ), CHF (10.15 $\mathrm{g}, \quad 25.3 \%)$ and AQF $(20 \mathrm{~g}, 50 \%)$ fractions. The data indicates that around half of the phytochemicals were polar in nature.

Total phenolic (TPC) and flavonoid (TFC) contents of D. indica: TPC and TFC of the bark extracts were calculated on the basis of standard gallic acid curve and the results were expressed as GAE/g of dried extractives. TPC of CME, CHF, PETF and AQF was found to be 90.2, 171.1, 52.1 and $158.1 \mathrm{mg}$ of $\mathrm{GAE} / \mathrm{g}$ of dried bark extract, respectively (Figure 1A). From the data it was shown that the phenolic content of CHF as well as AQF was higher than original extract $\mathrm{CME}$, hence chloroform fraction might serve as a good source for phenolics as well as antioxidants (Alam et al., 2016).

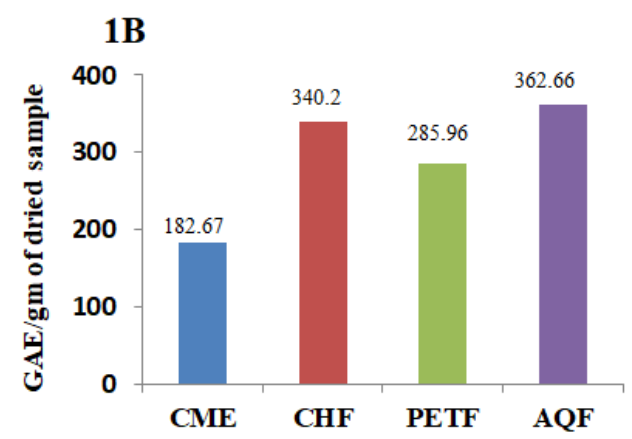

Figure 1. (A) Total phenolic and (B) Total flavonoid contents of CME and three fractions of $D$. indica (mg/g plant extract in GAE). 
The TFC of CME, PETF, CHF and AQF were 182.6, 285.9, 340.2 and $362.6 \mathrm{mg}$ of $\mathrm{GAE} / \mathrm{gm}$ of dried bark extract, respectively (Figure 1B). The data indicates that $\mathrm{CHF}$ contained two times higher amounts of flavonoids than that of $\mathrm{CME}$ and the results demonstrated that $D$. indica is a significant source of flavonoids.

Total antioxidant capacity (TAC) of CME and various fractions of D. indica: The TAC of CME and standard CA are represented in Figure 2A. The results showed that $\mathrm{CME}$ possessed comparable antioxidant activity to the standard CA (0.373 vs 0.804 ) at a concentration of $160 \mu \mathrm{g} / \mathrm{ml}$. Among the fractions, AQF showed the highest TAC (1.051) followed by $\mathrm{CHF}(0.88)$, and $\operatorname{PETF}(0.707)$ at 160 $\mu \mathrm{g} / \mathrm{ml}$ (Figure 2B). Our results demonstrated that all the extractives of $D$. indica possessed appreciable antioxidant activity.
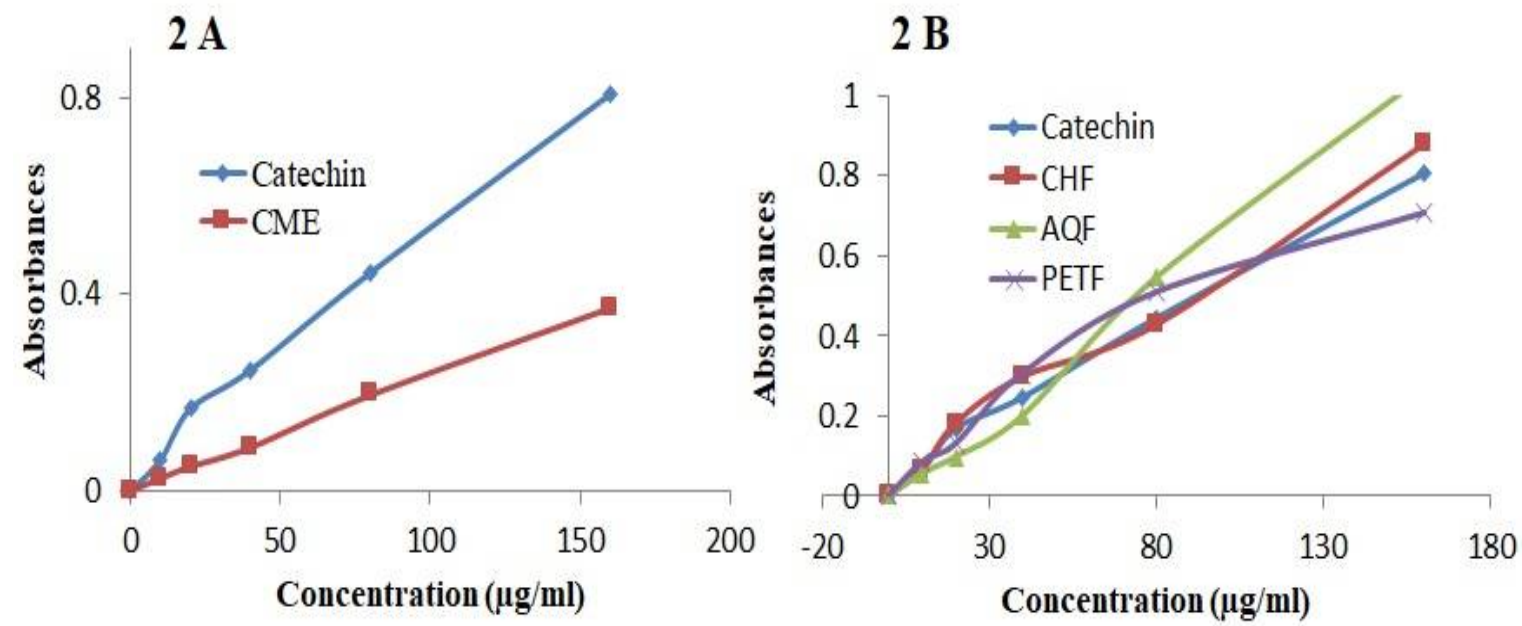

Figure 2. Total antioxidant activity of (A) CME and standard CA and (B) PETF, CHF, AQF and standard CA.

DPPH Free radical scavenging assay (DRSA) of $C M E$ and various fractions of $D$. indica: The results of DRSA of various fractions are shown in Table 1 where ascorbic acid was used as standard. From the table, the $\mathrm{IC}_{50}$ values of $\mathrm{CME}$ and fraction PETF, $\mathrm{CHF}, \mathrm{AQF}$ and ascorbic acid were found to be 23 , $61,2.5,1.5$ and $8 \mu \mathrm{g} / \mathrm{ml}$, respectively. Among the extractives, the significant scavenging activity was found in $\mathrm{AQF}$ and $\mathrm{CHF}$. Our observation demonstrated that all the extractives of bark of $D$. indica possessed significant DPPH free radical scavenging activity.

Hydroxyl radical scavenging activity (HRSA) of various fraction of $D$. indica: In the HRSA, scavenging activity percentage was calculated. It was observed that the activity was concentration dependent (Figure 3A). The $\mathrm{IC}_{50}$ values of $\mathrm{CME}$,
PETF, CHF, AQF and standard AA were found to be 86, 168, 42, 49 and $17.5 \mu \mathrm{g} / \mathrm{ml}$, respectively (Figure 3B). Among the fractions, the highest scavenging activity was found in $\mathrm{CHF}$ and AQF. Our observation demonstrated that all the extractives of bark of $D$. indica possessed significant hydroxyl free radical scavenging activity.

Ferric-reducing antioxidant capacity: The ferric reducing capacity (FRC) of the different extractives of $D$. indica is represented in Table 2. Among the fractions, CHF (2.418), AQF (2.262) and CME (2.157) showed higher reducing capacity than standard AA (1.793) at $160 \mu \mathrm{g} / \mathrm{ml}$. The reducing power of different extractives and standard AA showed the following order: $\mathrm{CHF}>\mathrm{AQF}>\mathrm{CME}>$ AA $>$ PETF. 

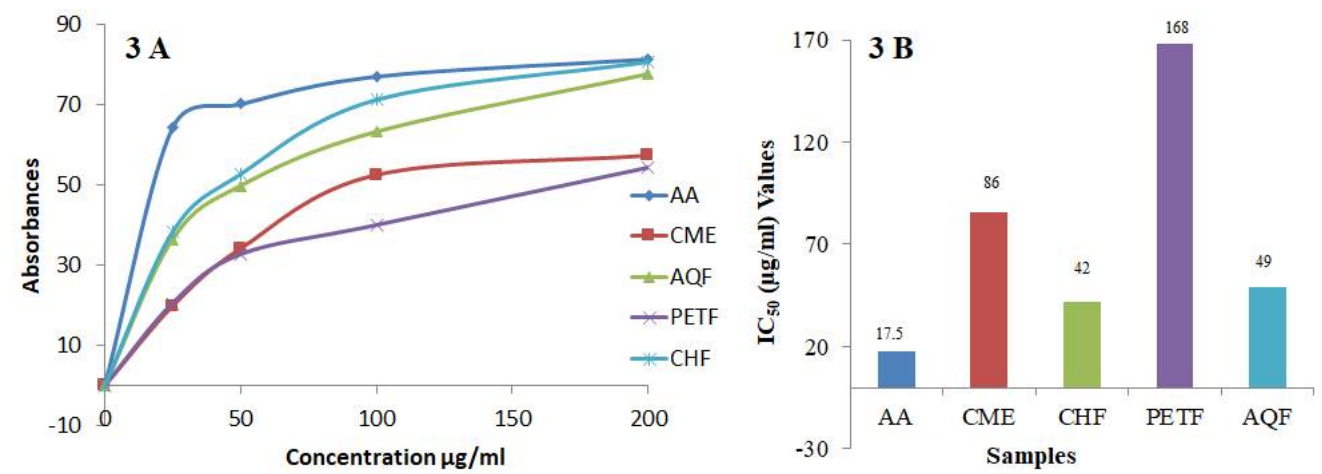

Figure 3. (A) Hydroxyl radical scavenging activity of standard AA, CME and various fractions at different concentrations and $(B) \mathrm{IC}_{50}(\mu \mathrm{g} / \mathrm{ml})$ values of different extractives and standard for hydroxyl radical scavenging activity.

Table 1. DPPH free radical scavenging activity (DRSA) of AA, CME and various fractions at different concentrations.

\begin{tabular}{lccccc}
\hline \multirow{2}{*}{ Conc. $(\mu \mathrm{g} / \mathrm{ml})$} & \multicolumn{5}{c}{ Sample with \% of scavenging (Mean \pm STD)* } \\
\cline { 2 - 6 } & AA & CME & PETF & CHF & AQF \\
\hline 100 & $96.3 \pm 0.20$ & $93.6 \pm 0.38$ & $86.7 \pm 2.58$ & $91.4 \pm 0.40$ & $91.6 \pm 0.14$ \\
50 & $96.2 \pm 0.20$ & $94.3 \pm 0.45$ & $39.6 \pm 5.87$ & $93.1 \pm 0.52$ & $93.4 \pm 0.56$ \\
25 & $96.2 \pm 0.68$ & $53.7 \pm 9.31$ & $14.8 \pm 3.25$ & $94.9 \pm 0.22$ & $93.2 \pm 0.39$ \\
12.5 & $95.7 \pm 0.26$ & $28.7 \pm 2.94$ & $8.4 \pm 1.58$ & $94.4 \pm 0.3$ & $87.2 \pm 2.26$ \\
6.25 & $34.7 \pm 16.03$ & $13.5 \pm 0.67$ & $5.5 \pm 0.56$ & $90.5 \pm 0.68$ & $86.0 \pm 2.16$ \\
3.124 & $23.7 \pm 1.93$ & $7.2 \pm 0.89$ & $3.6 \pm 0.87$ & $75.6 \pm 1.32$ & $81.4 \pm 0.82$ \\
\hline $\mathrm{IC}_{50}(\mu \mathrm{g} / \mathrm{ml})$ & $8 \pm 0.93$ & $23 \pm 1.13$ & $61 \pm 2.41$ & $2.5 \pm 0.99$ & $1.5 \pm 0.22$ \\
\hline
\end{tabular}

*The values are the mean \pm SD of triplicate experiment. AA, CME, PETF, CHF and AQF represent ascorbic acid, methanolic extract, pet-ether fraction, chloroform fraction and water fraction, respectively.

Table 2. Ferric reducing power capacity of ascorbic acid, CME and its three fractions at different concentrations.

\begin{tabular}{lccccc}
\hline \multirow{2}{*}{ Conc. $(\mu \mathrm{g} / \mathrm{ml})$} & \multicolumn{5}{c}{ Sample with Absorbance $($ Mean \pm STD)* } \\
\cline { 2 - 5 } & AA & CME & PETF & CHF & AQF \\
\hline 160 & $1.79 \pm 0.09$ & $2.15 \pm 0.08$ & $0.77 \pm 0.05$ & $2.41 \pm 0.19$ & $2.26 \pm 0.09$ \\
80 & $1.50 \pm 0.15$ & $1.57 \pm 0.19$ & $0.39 \pm 0.08$ & $2.23 \pm 0.11$ & $2.09 \pm 0.05$ \\
40 & $0.74 \pm 0.06$ & $0.87 \pm 0.05$ & $0.24 \pm 0.07$ & $1.96 \pm 0.13$ & $1.74 \pm 0.10$ \\
20 & $0.55 \pm 0.05$ & $0.48 \pm 0.15$ & $0.12 \pm 0.05$ & $1.15 \pm 0.01$ & $1.15 \pm 0.10$ \\
10 & $0.27 \pm 0.01$ & $0.19 \pm 0.05$ & $0.05 \pm 0.05$ & $0.73 \pm 0.12$ & $0.59 \pm 0.04$ \\
\hline
\end{tabular}

*The values are the mean \pm SD of triplicate experiment.

\section{Conclusion}

The crude methanolic extract of the bark of $D$. indica and its several fractions, especially chloroform fraction CHF showed remarkable antioxidant activity by inhibiting DPPH, hydroxyl and reducing power activities when compared with standards. Moreover, the chloroform fraction was found to have a noticeable quantity of polyphenols and flavonoids 
which play a major role in controlling antioxidant potentials of plant. In conclusion, the findings with significant radical scavenging as well as antioxidant activity of chloroform and aqueous fractions may provide valuable information for bioassay guided isolation of active principle responsible for particular activity.

\section{References}

Akter, M. J., Ali, S., Hasnin, I., Khatune, N. A. and Rahman, M. A. A. 2021. Cytotoxicity and sedative activity of steam bark of Dillenia indica L. Bang. Pharm. J. 24, 105-110.

Alam, A. H. M. K., Hossain, A. S. M. S., Khan, M. A., Kabir, S. R., Reza, M. A., Rahman, M. M., Islam, M. S., Rahman, M. A. A., Rashid, M. and Sadik, M. G. 2016. The antioxidative fraction of white mulberry induces apoptosis through regulation of p53 and NFkB in EAC cells. PLoS One 11, 0167536.

Das, R. R., Rahman, M. A., Al-Araby, S. Q., Islam, M. S., Rashid, M. M., Babteen, N. A., Alnajeebi, A. M., Alharbi, H. F. H., Jeandet, P., Rafi, M. K. J., Siddique, T. A., Uddin, M. N. and Zakaria, Z. A. 2021. The antioxidative role of natural compounds from a green coconut mesocarp undeniably contributes to control diabetic complications as evidenced by the associated genes and biochemical indexes. Oxid. Med. Cell. Longev 2021, 2021.

Franco, R., Navarro, G. and Martinez-Pinilla, E. 2019. Antioxidants versus food antioxidant additives and food preservatives. Antioxidants (Basel) 8, 542.

Kedare, S. B. and Singh, R. P. 2011. Genesis and development of DPPH method of antioxidant assay. $J$. Food Sci. Technol 48, 412-422.

Klein, S. M., Cohen, G. and Cederbaum, A. I. 1981. Production of formaldehyde during metabolism of dimethyl sulfoxide by hydroxyl radical-generating systems. Biochemistry 20, 6006-6012.

Kumar, S., Kumar, V. and Prakash, O. 2011. Microscopic evaluation and physiochemical analysis of Dillenia indica leaf. Asian Pac. J. Trop. Biomed. 1, 337-340.

Ordonez, A., Gomez, J., and Vattuone, M. 2006. Antioxidant activities of Sechium edule (Jacq.) Swartz extracts. Food chem. 97, 452-458.

Oyaizu, M. 1986. Studies on products of browning reaction: Antioxidant activities of products of browning reaction prepared from glucoamine. Jpn. J. Nutr. Diet. 44, 307-315.
Prieto, P., Pineda, M. and Aguilar, M. 1999. Spectrophotometric quantitation of antioxidant capacity through the formation of a phosphomolybdenum complex: specific application to the determination of vitamin E. Anal. Biochem. 269, 337-341.

Rahayu, S., Zahara, I., Afifah, A., P, K. and Supriyatin, S. 2020. Antioxidant capacity of Dillenia sp. leaf extract against DPPH (1,1- Diphenyl-2picryl Hidrazil) radical Antioxidant capacity of Dillenia sp. leaf extract against DPPH (1,1-Diphenyl-2picryl Hidrazil) radical. J. Phys. Conf. 1402, 1-8.

Rahman, M. M., Islam, M. B., Biswas, M. and Khurshid Alam, A. H. M. 2015. In vitro antioxidant and free radical scavenging activity of different parts of Tabebuia pallida growing in Bangladesh. BMC Res. Notes 8, 1-9.

Reza, A. S. M. A., Haque, M. A., Sarker, J., Nasrin, M. S., Rahman, M. M., Tareq, A. M., Khan, Z., Rashid, M., Sadik, M. G., Tsukahara, T. and Alam, A. K. 2021. Antiproliferative and antioxidant potentials of bioactive edible vegetable fraction of Achyranthes ferruginea Roxb. in cancer cell line. Food Sci. Nutr. 9, 3777-3805.

Saha, M. R., Alam, M., Hasan, R., Hossain, M., Akter, R. and Rana, E. 2009. In-vitro anti-oxidant activity of the leaves of Dillenia indica. Orient. Pharm. Exp. Med. 9, 277-284.

Saiful Yazan, L. and Armania, N. 2014. Dillenia species: A review of the traditional uses, active constituents and pharmacological properties from pre-clinical studies. Pharm. Biol 52, 890-897.

Sharifi-Rad, M., Anil Kumar, N. V., Zucca, P., Varoni, E. M., Dini, L., Panzarini, E., Rajkovic, J., Tsouh Fokou, P. V., Azzini, E., Peluso, I., Prakash Mishra, A., Nigam, M., El Rayess, Y., Beyrouthy, M. E., Polito, L., Iriti, M., Martins, N., Martorell, M., Docea, A. O., Setzer, W. N., Calina, D., Cho, W. C. and SharifiRad, J. 2020. Lifestyle, oxidative stress, and antioxidants: Back and forth in the pathophysiology of chronic diseases. Front. Physiol. 11, 694.

Wolfe, K. Wu, X. and Liu, R. H., 2003. Antioxidant activity of apple peels. J. Agric. Food Chem. 51, 609614.

Xu, X., Liu, A., Hu, S., Ares, I., Martínez-Larrañaga, M.R., Wang, X., Martínez, M., Anadón, A. and Martínez, M.-A. 2021. Synthetic phenolic antioxidants: Metabolism, hazards and mechanism of action. Food Chem. 353, 129488. 